\title{
Volume and volatility in the FX-market: Does it matter who you are?*
}

\author{
Geir H. Bjønnes ${ }^{\dagger} \quad$ Dagfinn Rime ${ }^{\ddagger}$ \\ Haakon O.Aa. Solheim ${ }^{\S}$
}

February 28, 2003

\begin{abstract}
The relationship between volume and volatility has received much attention in the the literature of financial markets. However, due to the lack of data, few results have been presented for the foreign exchange market. Further, most studies contain only aggregate series, and can not distinguish between the impact of different instruments or participants. We study the impact of volume on volatility in the the FX-market using a unique data set of daily trading in the Swedish krona (SEK) market. The data set covers 95 per cent of worldwide SEK-trading, and is disaggregated on a number of reporting banks' buying and selling in five different instruments on a daily basis over a period of nine years. We find that volume in general depict a positive correlation with volatility. However, the strength of the relationship depends on the instrument used and the identity of the reporting bank. In particular we find that it is the large Swedish banks that dominate the relationship. These banks are probably also the best informed banks. We interpret this is as evidence that heterogeneous expectations are important to understand the volume-volatility relationship.
\end{abstract}

Keywords: Volume volatility relation, microstructure, exchange rates JEL Classification: F31

*Data is kindly provided to us from the Sveriges Riksbank. We are very grateful to Antti Koivisto for helpful discussions and assistance with collecting the data set.

${ }^{\dagger}$ Stockholm Institute for Financial Research, email: geir.bjonnes@sifr.org.

${ }^{\ddagger}$ Norges Bank (Central Bank of Norway) and Stockholm Institute for Financial Research. email: dagfinn.rime@norges-bank.no.

${ }^{\S}$ Corresponding author. Norwegian School of Management (BI). email: haakon.o.solheim@bi.no. 


\section{Introduction}

This paper study the relationship between volume and volatility of in the exchange rate market. In the FX-market such research has until recently been difficult due to the lack of good trading data. In this paper we use a unique data set provided by Sveriges Riksbank (the Swedish central bank) that enables us to address both the importance of information arrivals and heterogeneous beliefs. The data is based on daily reporting from a number of primary dealers, both Swedish and foreign. Each primary dealer reports their total purchases and sales in five different instruments, (i) spot, (ii) outright forwards, (iii) short swaps (tomorrow-next), (iv) FX swaps, and $(v)$ options. ${ }^{1}$ The data covers as much as 95 per cent of all currency trading in Swedish kroner.

Studies from a number of different market settings suggest that there is a positive relationship between volatility and volume (see Karpoff, 1987). Due to the data problems there are few studies on the FX-market, and those who have actual volume data have only had access to limited parts of total volume. Goodhart and Figliuoli (1991) and Bollerslev and Domowitz (1993) both use the frequency of indicative quotes on the Reuters FXFX as a proxy of volume. Grammatikos and Saunders (1986) and Jorion (1996) use data on the number of futures contracts traded. Wei (1994) and Hartmann (1999) use Bank of Japan's set on brokered transactions in the Tokyo JPY/USD market. We can restate the volume-volatility findings with a much broader data set. A study using actual volume data is Galati (2000) who has BIS data from for seven developing countries. In general these studies suggest a positive relationship between volatility and volume consistent with evidence from other markets.

An important question is why the volume-volatility relationship arises. Three central contributions on the theory of the relationship between volume and volatility are Clark (1973), Epps and Epps (1976) and Tauchen and Pitts (1983). Clark (1973) introduces the mixture of distribution hypothesis, where the correlation between volume and volatility arises due to arrival of new information which drives both exchange rate changes and volume. Epps and Epps (1976) provide a second, and complementary explanation. They argue that that the volume-volatility relationship is due to the extent which traders disagree when they revise their reservation prices. More heterogenous beliefs should cause more volatility.

Tauchen and Pitts (1983) provide a model that combines these two features. They point out that volume might change over time for different

\footnotetext{
${ }^{1} \mathrm{~A}$ short swap is a contract to be delivered within two days, e.g. before a spot contract.
} 
reasons. There might be an increase in the number of traders, arrival of new information or heterogenous beliefs between different traders. The volumevolatility relationship depends on why volume changes, e.g. a trend in volume due to an increase in the number of traders in the market should lead to lower volatility due to higher liquidity.

Foster and Viswanathan (1990) and Shalen (1993) provide models where dispersion of beliefs create both more price variability and excess volume. Shalen (1993) argues that uninformed traders increase volatility because they cannot differentiate liquidity demand from fundamental value change. The literature on asymmetric information models (e.g. Kyle, 1985; Admati and Pfleiderer, 1988) emphasize the role of heterogenous agents in the pricing process.

This paper makes three contributions. First, we document a positive relationship between volume and volatility using data that covers almost all currency trading in SEK. Although a positive volume-volatility relationship is documented for the FX-market i previous studies, this is to our knowledge the first time such a relationship is documented for one of the the ten largest currency markets using such an extensive set of volume data. ${ }^{2}$

Second, we are able to separate total volume into different instruments. The standard assumption is that the spot market should be the important market for determining the exchange rate. However, previous studies have used data from both the spot market and the forward market. We show that it is indeed the spot volume that is most important. However, we also find some indications that forward and option volume are correlated with spot exchange rate volatility. In case of the forward market we suggest the following intuition: All trades in the forward market are initiated by customers of the banks. This again leads the bank to trade spot in the interbank market to hedge. Hence, the initial information release may first be picked up by forward volume.

Last, but maybe most important, is that we examine the role of heterogeneity in explaining volatility. This is possible since we have the volume of each of the different reporting banks. That means that we have aggregates of volume that is actually observable in the market, however only to the reporting bank. This is truly private information. We address this both by regressing volatility on each banks volume in separate regressions, and by grouping banks into different categories and regressing volatility on these aggregated group volumes. We find that it is volume of large Swedish banks

\footnotetext{
${ }^{2}$ According to Bank of International Settlements (2002), the Swedish currency market is the eight largest market. The Swedish market is for example larger than the emerging markets studied in Galati (2000).
} 
tend to create the most volatility. These banks are also most likely the best informed since the have the largest customer base (Lyons, 2001), and indicate a role for heterogenous beliefs for volatility. The importance of heterogenous information for understanding exchange rate changes is also documented recently by Evans and Lyons (2002).

Studies from other market settings also suggest that heterogeneity among the market players may be important to understand volatility (see e.g. Grinblatt and Keloharju, 2001). Bessembinder and Seguin (1993) and Daigler and Wiley (1999), both studying futures markets, document the importance of different types of traders for explaining the volume-volatility relationship. Daigler and Wiley (1999) find that trade "speculators", i.e. traders located outside the actual market, tend to be more correlated with volatility than trade by investors in the market. Since these "outsiders" may be interpreted as noise-traders this result is different from ours.

The paper is organized as follows. Section 2 gives a detailed presentation of our data. In Section 3 we derive testable hypothesis and present the results. Section 4 concludes.

\section{Data}

In this section we start with describing our volume data. We then present the macro variables applied in the analysis.

\subsection{Volume data}

The Riksbank receives daily reports from a number of Swedish and foreign banks (currently 13) on their buying and selling of five different instruments. The reported series is an aggregate of Swedish krona (SEK) trading against all other currencies, measured in krona, and covers $90-95 \%$ of all worldwide trading in the SEK. Close to $100 \%$ of all interbank trading and $80-90 \%$ of customer trading are made in SEK/EUR. In our analysis we will therefore focus on the SEK/EUR exchange rate.

Aggregate volume information is not available to the market. FX-markets are organized as multiple dealer markets, and have low transparency. The specific reporter will only know her own volume and a noisy signal on aggregate volume that they receive through brokers. Reporting banks do obtain some statistical summaries of volume aggregates from the Riksbank, but only with a considerable lag. The data set used in this paper is not available to market participants. 
The data set stretch from January 1, 1993 to December 31, 2001. However, the reporting procedure was revised after 1994. In most regressions we will therefore use observations from January 1, 1995. Figure 1 shows the total gross volume in the spot market and the absolute returns in the exchange rate. There is a clear relationship between volume and volatility, especially in periods of high volatility like 1996/97 and in the fall of 1998. We also note that there is no clear trend in the series.

The five instruments are spot, forward, options, short swaps (tomorrow/next) and standard swaps. The short swap is mainly used as a liquidity control instrument when one needs cash with delivery in less than two days (the time of a standard spot transaction). Table 1 gives an indication of the relative usage of the different instruments. We note that as a percentage of total volume in the market, short swaps is the largest category, followed by spot trading. Forward and option trading makes up much smaller parts of total market volume.

Table 1: The importance of different instruments. Sample: 1.1995-12.2001

\begin{tabular}{lrrrrr}
\hline $\begin{array}{l}\text { as \% of tot. volume } \\
\text { 01.95-12.01 }\end{array}$ & Spot & Forward & Short swap & Swap & Option \\
\hline Mean & 0.29 & 0.06 & 0.36 & 0.27 & 0.03 \\
St.dev. & 0.10 & 0.03 & 0.10 & 0.07 & 0.02 \\
Maximum & 0.76 & 0.40 & 0.64 & 0.58 & 0.25 \\
Minimum & 0.10 & 0.01 & 0.02 & 0.03 & 0.00 \\
\hline
\end{tabular}

Numbers are percentages of total volume calculated on a daily basis.

The reporting banks are anonymized. However, we can distinguish between Swedish banks, foreign banks, and branches of foreign banks located in Sweden. The reporters are the main liquidity providers in the SEK-market. They are de facto primary dealers in this market. At most there are 15 reporting banks active in the market.

Because of confidentiality reasons we can not display detailed information on the size of each bank. However, only five banks are active over the whole period from 1993 to 2001. These are four Swedish reporters and one branch. Table 2 display their market share. Two of the banks are clearly more important than the other three. These are the two Swedish banks $S 1$ and $S 2$. Together these two banks control between 40 and 50 per cent of the market. Foreign reporters have controlled between 25 and 30 per cent of the market during the last six years. 
Figure 1: Gross spot volume and squared returns in the SEK/EUR
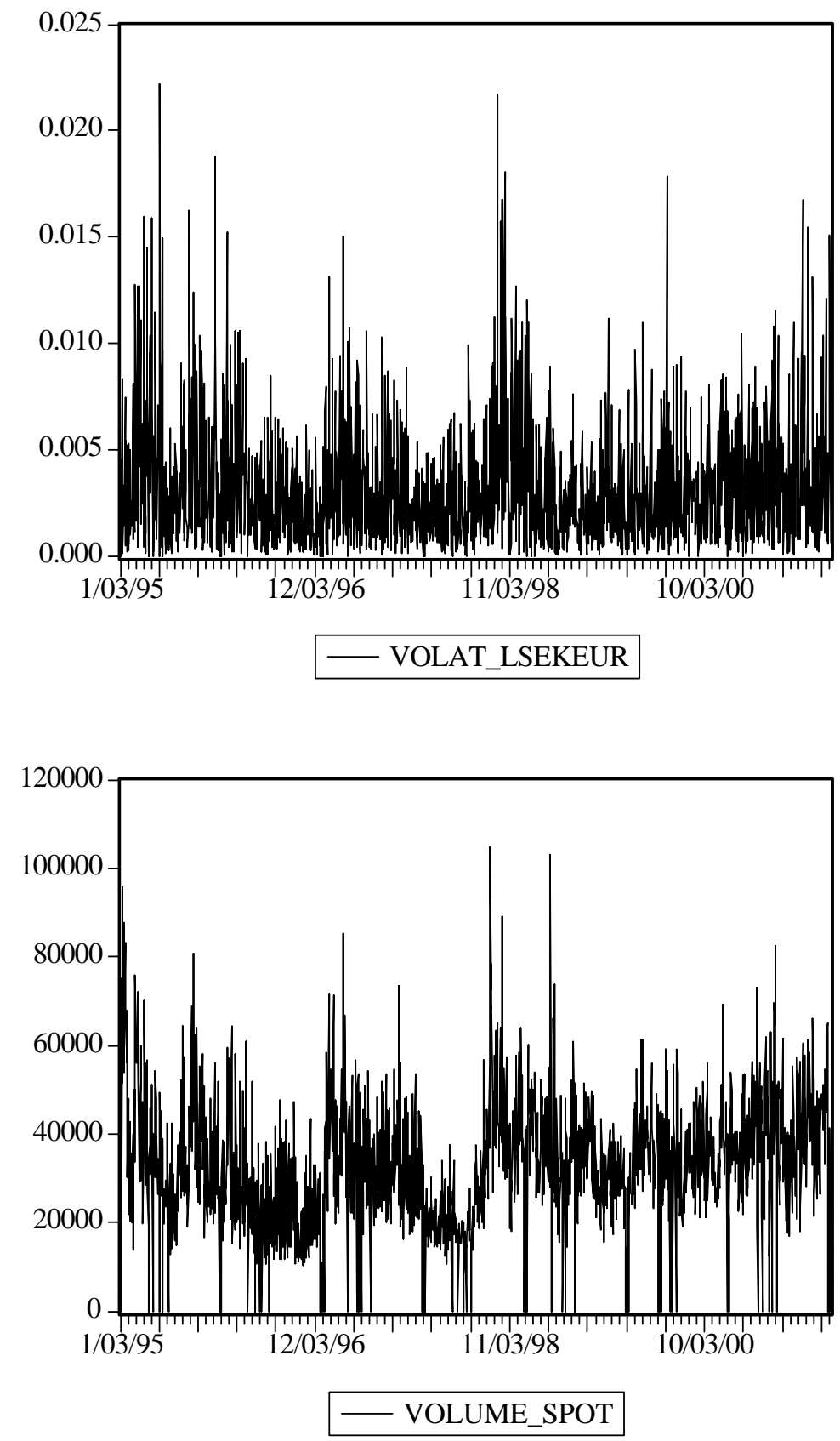

volume_spot: gross spot volume,

volat_lsekeurc: absolute returns of the log of the SEK/EUR, close to close. 
Table 2: The importance of different primary dealers.

\begin{tabular}{lrrr}
\hline $\begin{array}{l}\text { as \% of tot. volume } \\
\text { 01.95-12.01 }\end{array}$ & $\begin{array}{r}\text { S1+S2+S3 } \\
+ \text { S4+B1 }\end{array}$ & S1+S2 & $\begin{array}{l}\text { Foreign } \\
\text { reporters }\end{array}$ \\
\hline Mean & 0.64 & 0.43 & 0.27 \\
St.dev. & 0.14 & 0.10 & 0.18 \\
Maximum & 1.00 & 0.71 & 0.74 \\
Minimum & 0.22 & 0.13 & 0 \\
\hline 01.93-12.94 & & & \\
\hline Mean & 0.84 & 0.60 & 0.01 \\
St.dev. & 0.04 & 0.06 & 0.02 \\
Maximum & 0.95 & 0.80 & 0.13 \\
Minimum & 0.66 & 0.41 & 0 \\
\hline
\end{tabular}

Numbers are percentages of total volume calculated on a daily basis.

\subsection{Macrodata}

In the volatility regressions we use the absolute value of return. ${ }^{3}$ Return is measured as the change in the log of the exchange rate from close to close. ${ }^{4}$ Note that the SEK has been floating freely since November 1992.

Figure 2: The $\log$ of the SEK/EUR exchange rate and the Swedish and German bond spread
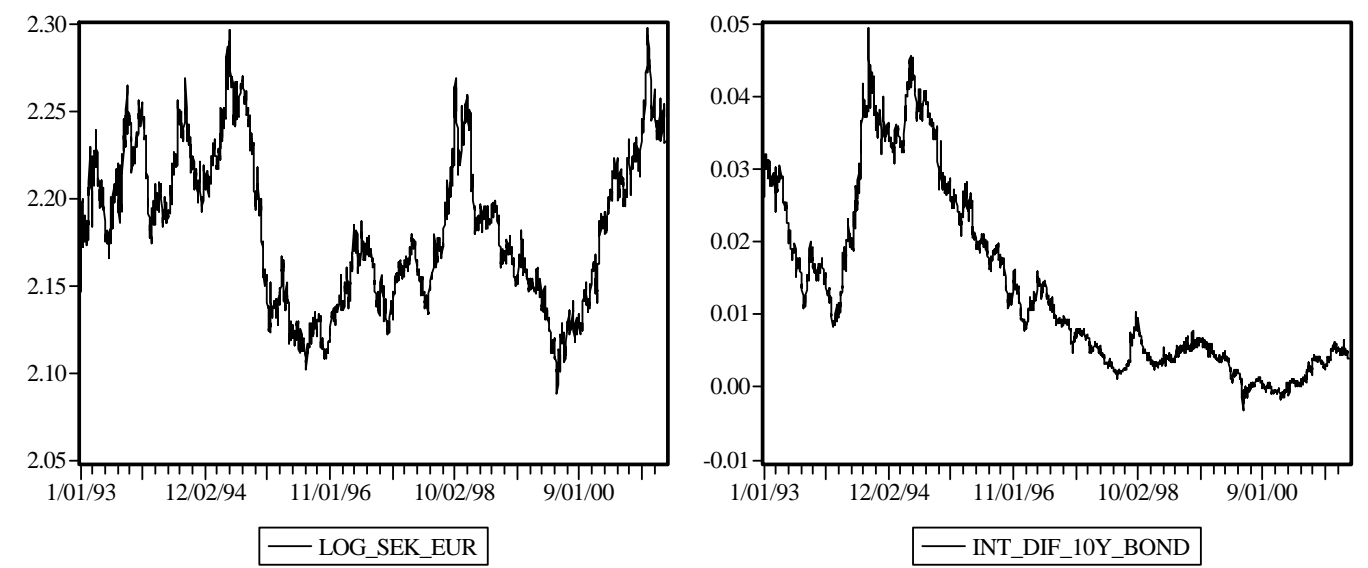

\footnotetext{
${ }^{3}$ Using squared return does not affect the results. Other potential measures for volatility is intra-day high-low or implied volatility from option prices, however such data is not available for the SEK/EUR market.

${ }^{4}$ For the period prior to January 1, 1999 we use SEK/DEM. The exchange rate is indexed to EUR equivalent terms (SEK/DEM*1.95583). Before 1999 DEM played the same role as EUR does at present.
} 
Figure 3: The absolute return in SEK/EUR and USD/EUR
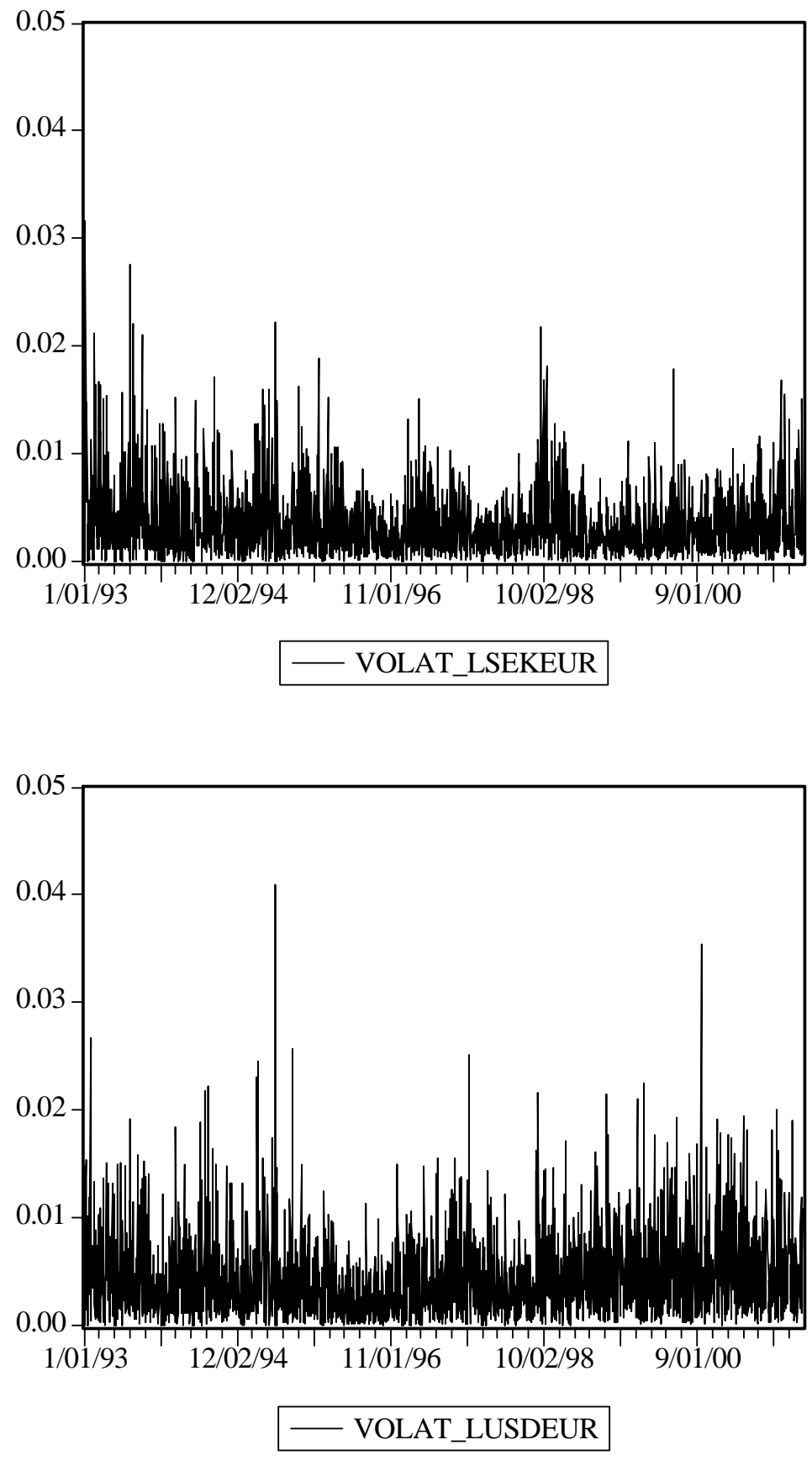

volat_lsekeur: absolute returns of the log of the USD/EUR, close to close, volat_lusdeur: absolute returns of the log of the SEK/EUR, close to close. 
In figure 2 we depict the exchange rate together with the 10 year bond spread between Sweden and Germany. In the period after the floating in November $1992^{5}$ and the period after the Russian moratorium in August 1998 volatility in the FX-market were high. There was strong depreciationary pressure during 2000 and 2001. Over the period as a whole the exchange rate has moved within a range of 21 per cent from top to bottom. The standard deviation of daily return over the period has been about 0.4 per cent, with a maximum daily return of 3.2 per cent. The bond spread gives an indication of the macroeconomic developments in Sweden over this period. It has been falling from nearly 5 per cent in 1993 to a current spread fluctuating around zero. This might reflect the implementation of a credible inflation target by the Swedish Riksbank. Sweden introduced an inflation target in 1993. The current target is set by law to be 2 per cent, with a band of $+/-1$ per cent.

According to the statistics from the BIS 2001 survey of the foreign exchange market, the Swedish market is the eight largest currency market in the world. However, the SEK is still a small currency compared to the EUR, the USD or the JPY. An interesting question is to which extent the volatility in the SEK/EUR market is the reflection of volatility in the the relative price of SEK to EUR and to which extent it is the result of volatility in the EUR on a broader scale. One could e.g. think that a movement in the USD/EUR rate would trigger expectations of a similar movement in the SEK/EUR rate. In figure 3 we show the absolute return in the SEK/EUR and the USD/EUR markets. There is evidence of some correlation between the two series. The correlation over the period from January 1993 to December 2001 is 0.19 .

\subsection{Expected vs. unexpected volume}

As pointed out above, Tauchen and Pitts (1983) differentiate between an increase in volume due to an increase in the number of traders and an increase in volume due to e.g. new information. An increase in volume due to and increase in the number of traders can be interpreted as "expected volume". Expected volume should primarily increase liquidity, and should have little impact on volatility. Bessembinder and Seguin (1992) and Hartmann (1999) document the importance of unexpected volume to explain the volume-volatility relationship.

The standard method to distinguish between expected and unexpected volume is to identify systematic time-series behaviour in the volume data, i.e. using an ARIMA-model. Using stationarity tests like the augmented

\footnotetext{
${ }^{5}$ From 1990 till November 1992 the SEK was fixed to the ECU. In November 1992 Sweden experienced a speculative attack, and the SEK was allowed to float.
} 
Dickey-Fuller or the Phillips-Perron we find no evidence of non-stationarity. However, when we estimate an ARMA-model on the volume series, the ARroot tends to close to or outside the unit circle. At the same time we find that the MA coefficient is close to -1 .

Similar observations are made by Hartmann (1999). Hartmann has volume data reported from Tokyo based brokers, covering trading in JPY/USD over the the period from 1986 to 1994. He report that the series are stationary according to standard tests, however the AR-roots are have a unit root and the MA is close to -1 . According to Hartmann the fact that the MA is close to -1 might distort the stationarity tests. He therefore argues that one should threat the series as non-stationary.

Hartmann (1999) argues that an $\operatorname{ARIMA}(9,1,1)$ gives the best fit on his data. This process seems to give a good fit also on our series. Further, Hartmann argues that an $\mathrm{ARCH}(3)$ process removes ARCH/GARCH effects from his series. Also this feature can be replicated in our data. The results of the regressions are reported in table 15 in the appendix.

To the ARIMA $(9,1,1)$ model we add a constant and a Monday dummy. Chang, Pinegar and Schachter (1997) document that there tends to be weekday patterns in volume data. Harris and Raviv (1993) have a model that predicts an increase in the volume on Mondays, as dispersion of beliefs are higher after a period of closed markets. Foster and Viswanathan (1990) predict that volume on Mondays will be lower than Tuesdays, due to the fact that private information accrues over weekends, while public information does not. Testing for four weekday dummies, we find that only the Monday-dummy is of special importance. In general we find that the Monday effect on volume is negative, in accordance with the predictions of Foster and Viswanathan (1990).

Our model of expected volume has a reasonable fit. For most series we find a $R^{2}$ between 30 and 40 per cent. We use the fitted values as "expected", and the residual as "unexpected".

\section{Results}

Although there seems evident from figure 1 that there is an relation between volume and volatility, when testing for information theoretic explanations we need to control for the volatility that is expected and hence can not be driven by new information or revisions in beliefs. Expected volatility is modelled using a standard $\operatorname{GARCH}(1,1)$ regression on the SEK/EUR return. The conditional variance from these regressions is the time-series forecast of risk, and is included in the regressions as "GARCH". The regression is reported 
Table 3: Correlation matrix - unexpected spot volume

\begin{tabular}{lrrrrr}
\hline & Total spot & S1 & S2 & S3 & S4 \\
\hline Total spot & 1 & & & & \\
S1 & 0.68 & 1 & & & \\
S2 & 0.76 & 0.56 & 1 & & \\
S3 & 0.50 & 0.33 & 0.41 & 1 & \\
S4 & 0.64 & 0.49 & 0.59 & 0.41 & 1 \\
B1 & 0.38 & 0.24 & 0.27 & 0.25 & 0.28 \\
\hline
\end{tabular}

"Total spot" is total unexpected spot volume aggregated over the reporting banks, "S1", "S2" "S3", "S4" and "B1" is total unexpected spot volume of Swedish Bank 1, 2, 3 and 4 and Branch 1 respectively.

in the appendix in table 16 .

All reported regressions are estimated using a GMM. The instrument matrix is specified in each regression table. Note that we here use generated regressors. The distinction between expected and unexpected volume and the GARCH term are estimated in separate regressions. Using generated regressors might bias the parameter estimates. All results should therefore be interpreted with care. We do however find that the results for the volume terms are stable with regard to choice of estimation methods. ${ }^{6}$ Further, the important issue in our discussion is the comparison of volume from different groups - not the coefficient of volume itself. We have no reason to believe that a possible bias in the volume coefficient should be different between different groups.

In all regressions we run a volatility measure (absolute value of return) on expected and unexpected volume; "GARCH", which is the one period lagged value of the conditional variance of returns; D1, which is a Monday dummy; and we also include the absolute return of the USD/EUR exchange rate. ${ }^{7}$

Table 3 shows a correlation matrix between five different volume aggregates. As we see, the selected volume series are highly correlated. This creates a problem of multicolinearity in the analysis of bank-heterogeneity. It might therefore be problematic to include different volume aggregates in the same regression. Instead we run separate regressions of volatility on the

\footnotetext{
${ }^{6}$ We use GMM since there is evidence of heterogeneity. Using OLS instead does not change any of the results. In addition to the reported regressions we have estimated the regressions endogenising the GARCH term by estimating a $\operatorname{GARCH}(1,1)$ model and including the ARCH-M variance term in the regression. This has no qualitative impact on the results. One should however note that there is some evidence of Chow-forecast instability in the regressions. This can be corrected by including a number of dummies. Such inclusions do not seem to have much effect on the volume parameters. Recursive regressions reveal that parameter stability in the volume parameters reported is good.

${ }^{7}$ Using squared returns instead of absolute returns give similar results.
} 
volume aggregates for each bank. However, we also report results where we group banks together.

The rest of this section provides results from estimations of volatility on volume in different instruments and volume from different reporters or groups of reporters.

\subsection{Instruments}

The most common approach to estimating the volume-volatility relationship would be to regress the volatility of spot exchange rates on some measure of spot volume, e.g. Jorion uses future market volume as a proxy while Galati use spot volume. A reasonable a priori assumption is that a volume-volatility relationship for the spot exchange rate should be dominated by transactions in the spot market. Lyons (2001) describes the spot market as the driving force of the FX-market. For comparison, a swap transaction has no "order flow" effect, as it is just two opposing transactions being made at the same time.

However, volume in other instruments than spot may reflect arrival of new information or dispersion of beliefs, and thereby also be informative about spot volatility. As an example think of speculation by customers. This is most commonly done by forward trading, which again will trigger spot-trading in the interbank market. In this case the information effect might primarily be picked up by the forward volume. This analogous to the informational advantage of banks with huge customer order flow that is reported in recent surveys by Cheung and Chinn (2001). Similarly, option volume may reflect changes in beliefs about the true spot volatility, potentially due to new information. So it could be interesting to see whether other instruments also can explain volatility. But, and this is a big but, since forwards, options and swaps also are hedging instruments we could have the reverse causality.

Table 4 and 5 reports the estimations of volatility on the volume of all instruments and on volume for each of the five instruments respectively. We estimate both with the instruments together and in separate regressions due to problems with multicollinearity.

First, despite the inclusion of expected variance in the model, there is a positive correlation between volume and volatility. We focus on unexpected volume. Table 4 show that there are significant and positive coefficients for spot and option volume. The coefficient of short swaps is significant, but negative.

Table 5 reports the separate regressions for each of the instruments. We find a correctly signed and significant relationship in three of the five instruments: spot, forwards and options. First, note that the fit of the regression 


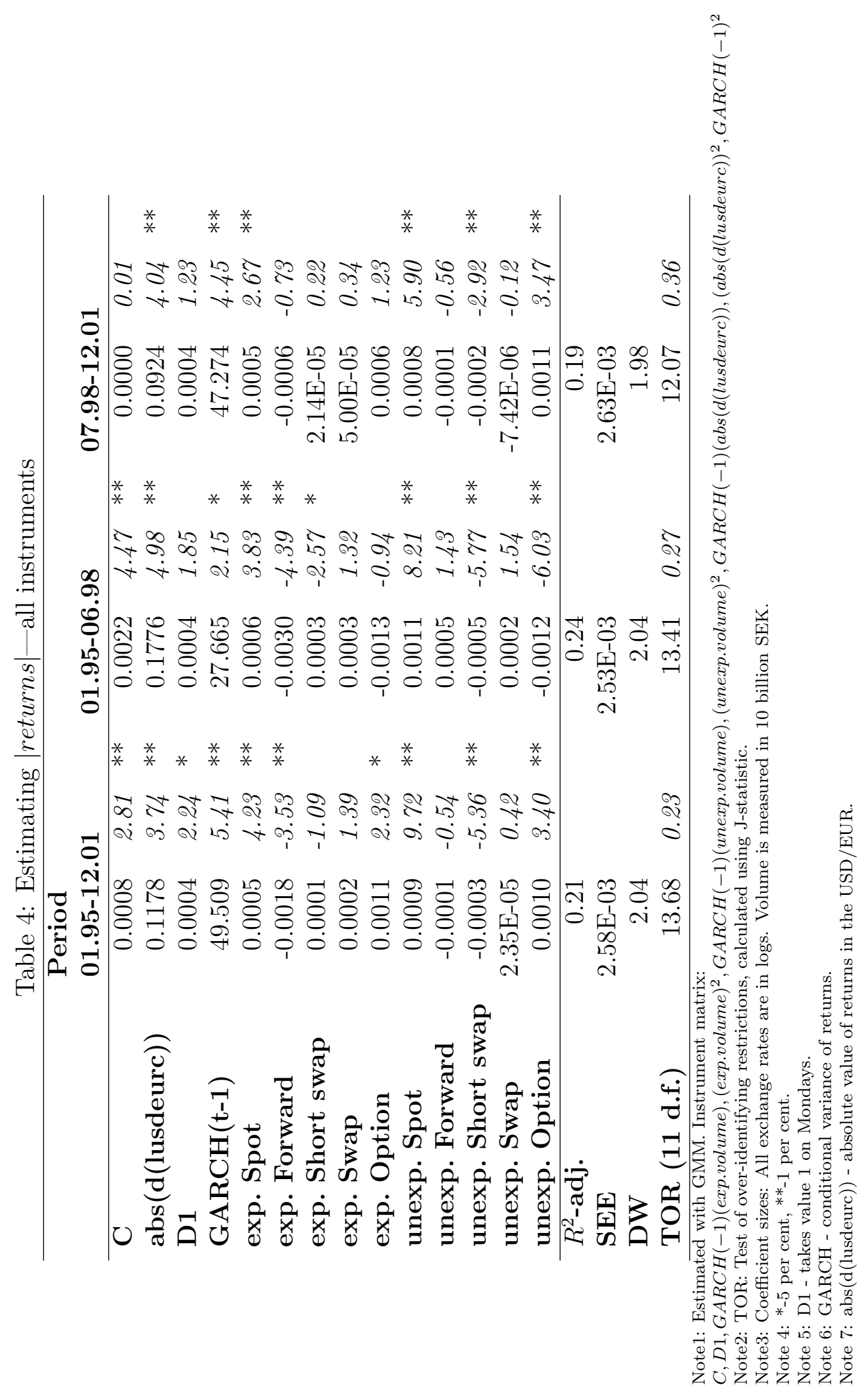




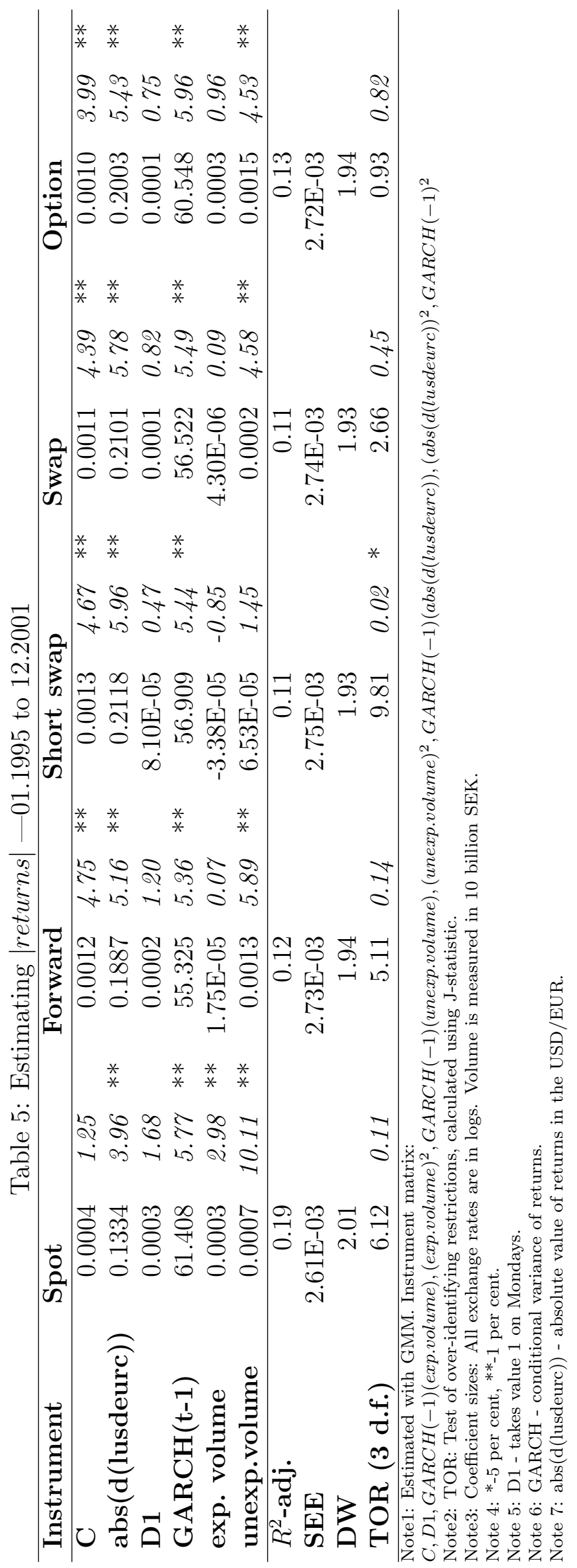


is best for the regression using spot volume and that the coefficients on spot volume is similar as in table 4. Second, the significant effect from short swaps have disappeared. This is somewhat reassuring. Short swaps are primarily liquidity instruments, while ordinary swaps are more interest rate related instruments. It is much harder to think about information releases that might trigger swap volume instead of spot volume, while still having implication for spot exchange rate, than it is with forwards and options. Finally, both forwards and options are significant and correctly signed. Given the ambiguous effect from these instruments in the combined regression we use only spot volumes in later regressions.

The $R^{2}$ values are in the range between 10 and 25 per cent. This is in line with other studies that regress volatility on volume. According to Daigler and Wiley (1999) $R^{2}$ values in such regressions typically range from 10 to 35 per cent.

Table 6: Size effects - 01.1995 to 12.01

\begin{tabular}{lrrrr}
\hline & St.dev. & Parameter & $\begin{array}{l}\text { Implied } \\
\text { volatility }\end{array}$ & \multicolumn{1}{l}{$\begin{array}{l}\text { \% of } \\
\text { FX-vola. }\end{array}$} \\
\hline abs. returns & $2.91 \mathrm{E}-03$ & & & \\
exp. Spot & $\mathbf{8 7 6 9}$ & $\mathbf{4 . 5 3 E - 0 4}$ & $\mathbf{3 . 9 7 E - 0 4}$ & $\mathbf{1 3 . 6 6}$ \\
exp. Forward & $\mathbf{3 0 2 0}$ & $\mathbf{- 1 . 7 5 E - 0 3}$ & $\mathbf{- 5 . 2 8 E - 0 4}$ & $\mathbf{- 1 8 . 1 6}$ \\
exp. Short swap & 20030 & $-9.38 \mathrm{E}-05$ & $-1.88 \mathrm{E}-04$ & -6.46 \\
exp. Swap & 16741 & $1.75 \mathrm{E}-04$ & $2.93 \mathrm{E}-04$ & 10.07 \\
exp. Option & 2731 & $1.07 \mathrm{E}-03$ & $2.92 \mathrm{E}-04$ & 10.05 \\
unexp. Spot & $\mathbf{1 0 3 7 7}$ & $\mathbf{9 . 1 2 E - 0 4}$ & $\mathbf{9 . 4 6 E - 0 4}$ & $\mathbf{3 2 . 5 3}$ \\
unexp. Forward & 3706 & $-1.11 \mathrm{E}-04$ & $-4.11 \mathrm{E}-05$ & -1.41 \\
unexp. Short swap & $\mathbf{1 5 3 7 9}$ & $\mathbf{- 2 . 9 4 E - 0 4}$ & $\mathbf{- 4 . 5 2 E - 0 4}$ & $\mathbf{- 1 5 . 5 4}$ \\
unexp. Swap & 12459 & $2.35 \mathrm{E}-05$ & $2.93 \mathrm{E}-05$ & 1.01 \\
unexp. Option & $\mathbf{2 9 6 4}$ & $\mathbf{9 . 9 2 E - 0 4}$ & $\mathbf{2 . 9 4 E - 0 4}$ & $\mathbf{1 0 . 1 1}$ \\
GARCH & $\mathbf{1 . 0 4 E - 0 5}$ & $\mathbf{4 9 . 5 0 9}$ & $\mathbf{5 . 1 5 E - 0 4}$ & $\mathbf{1 7 . 7 0}$ \\
abs. returns USD & $\mathbf{4 . 0 5 E - 0 3}$ & $\mathbf{0 . 1 1 7 8}$ & $\mathbf{4 . 7 7 E - 0 4}$ & $\mathbf{1 6 . 4 1}$ \\
"Per cent of FX-volatility" is the ratio of implied volatility over the standard deviation of absolute returns \\
in the SEK/EUR. \\
All parameters are collected from table 4.
\end{tabular}

The size effects of the parameter values in table 4 are not obvious. To give an indication of size effects we perform an illustrative exercise. One standard deviation of absolute returns is $2.19 \cdot 10^{-3}$. If we take one standard deviation of the GARCH term $\left(1.04 \cdot 10^{-5}\right)$ and multiply this with the parameter of value of 49.509 (in the case of the spot-volume regression), we obtain $5.15 \cdot 10^{-4}$. This indicates that in this regression the GARCH term can explain about 18 per cent of the volatility in returns. A similar procedure for unexpected spot 
volume gives a factor of 33 per cent. We also see that unexpected volume is a more important explanatory factor than is expected volume. This indicates that unexpected volume is indeed an important explanatory factor, at least compared with the GARCH term. A list of calculations is performed in table 6 . We see that spot volume explains almost three times as much of volatility than what does option volume. The explanatory power of swap volume is only a fraction of the above numbers.

\section{$3.2 \quad$ Reporters}

Recent research from the microstructure approach to foreign exchange indicate that traders have different strategies and information (see e.g. Lyons, 1995; Bjønnes and Rime, 2001). It is also reasonable to assume that different banks will focus on specific types of trading strategies (Cheung and Chinn, 2001). However, banks are mostly unwilling to reveal their explicit strategies, so this is a topic where few results have been published.

We have bank-specific volumes and can therefore test for differential impact from banks on volatility directly. A priori it is not obvious that different reporters should be correlated differently with volatility. If the increase in number of transactions is due to arrival of public information, we should expect a simultaneous increase in trading from all reporters. However, if dispersion of beliefs is an important feature for generating the volume-volatility relationship then the trading volume of some reporters might be more closely correlated with volatility than the volume of other reporters. Hence, we can differentiate between the two potential sources of the volume-volatility relationship.

Tables 7-9 reports finding for the five banks that are represented in the total sample, as well as regressions on total spot volume as a base comparison. ${ }^{8}$ To assure a test of parameter stability we report tests on four different time intervals. We estimate over the period 1993-1994 and over the period 19952001. For the last interval we also conduct estimations on two sub-samples of equal length. As one can see there is high consistency across the time intervals (see table 17 in the appendix). However, $R^{2}$ is substantially lower for the 1993-94 period. This can maybe be explained by the way spot-volume was reported in this period.

Table 10 reports estimations on 13 additional banks. These are banks that are only in our sample for shorter periods of time. Mostly these are banks of much lesser size than the five banks reported in tables 7-9. For

\footnotetext{
${ }^{8}$ We only use spot volumes here since last section showed that most of the effect comes from spot volume.
} 


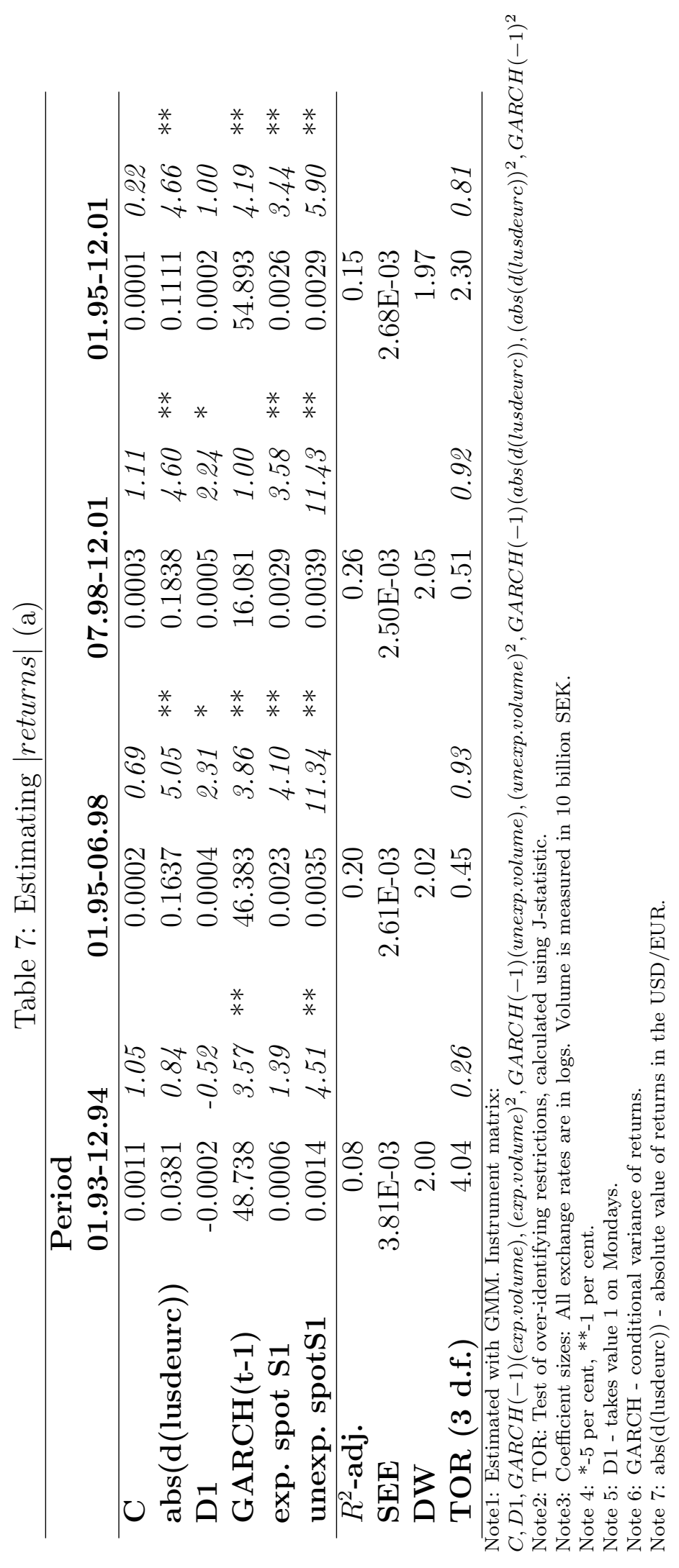




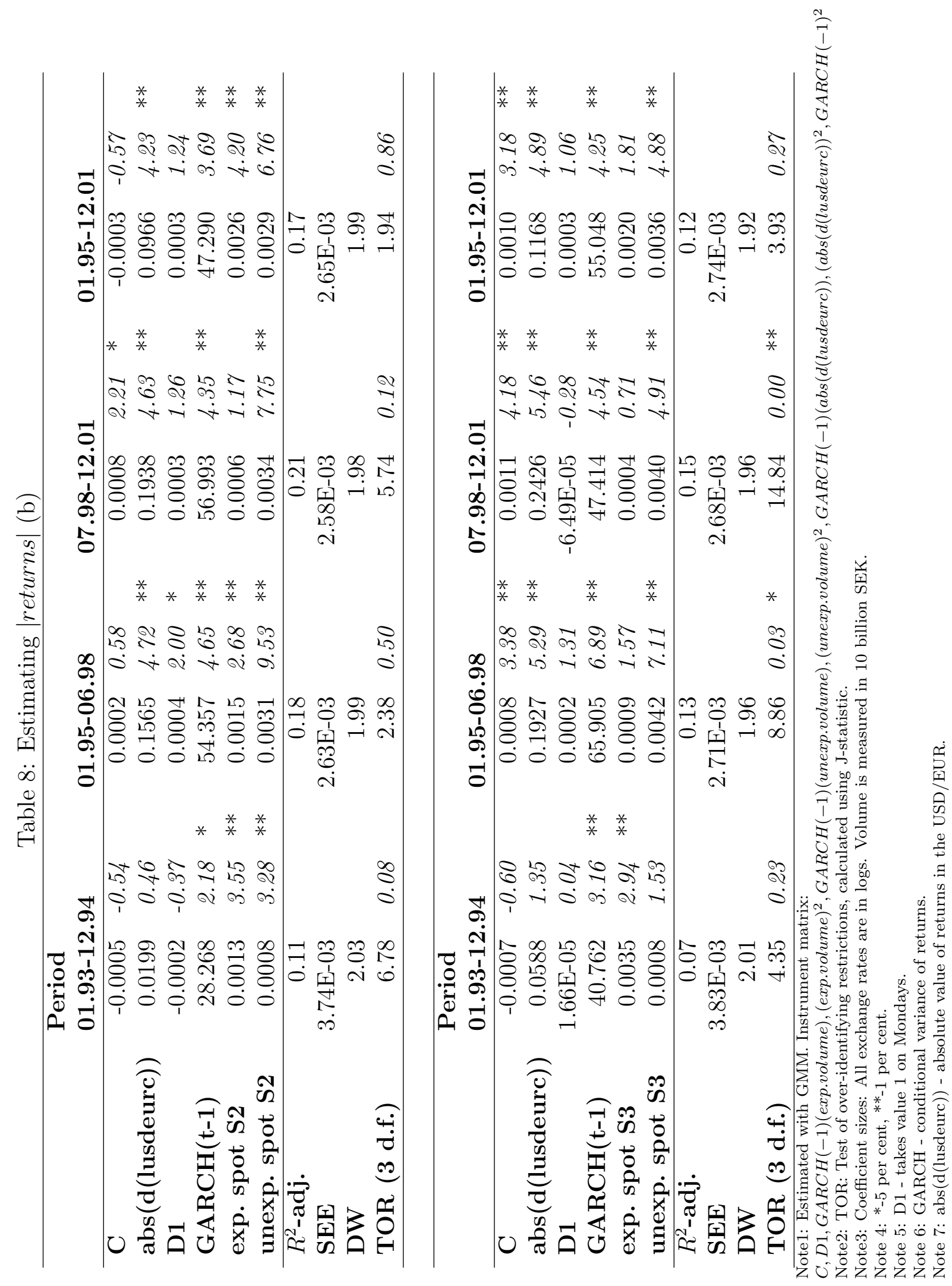




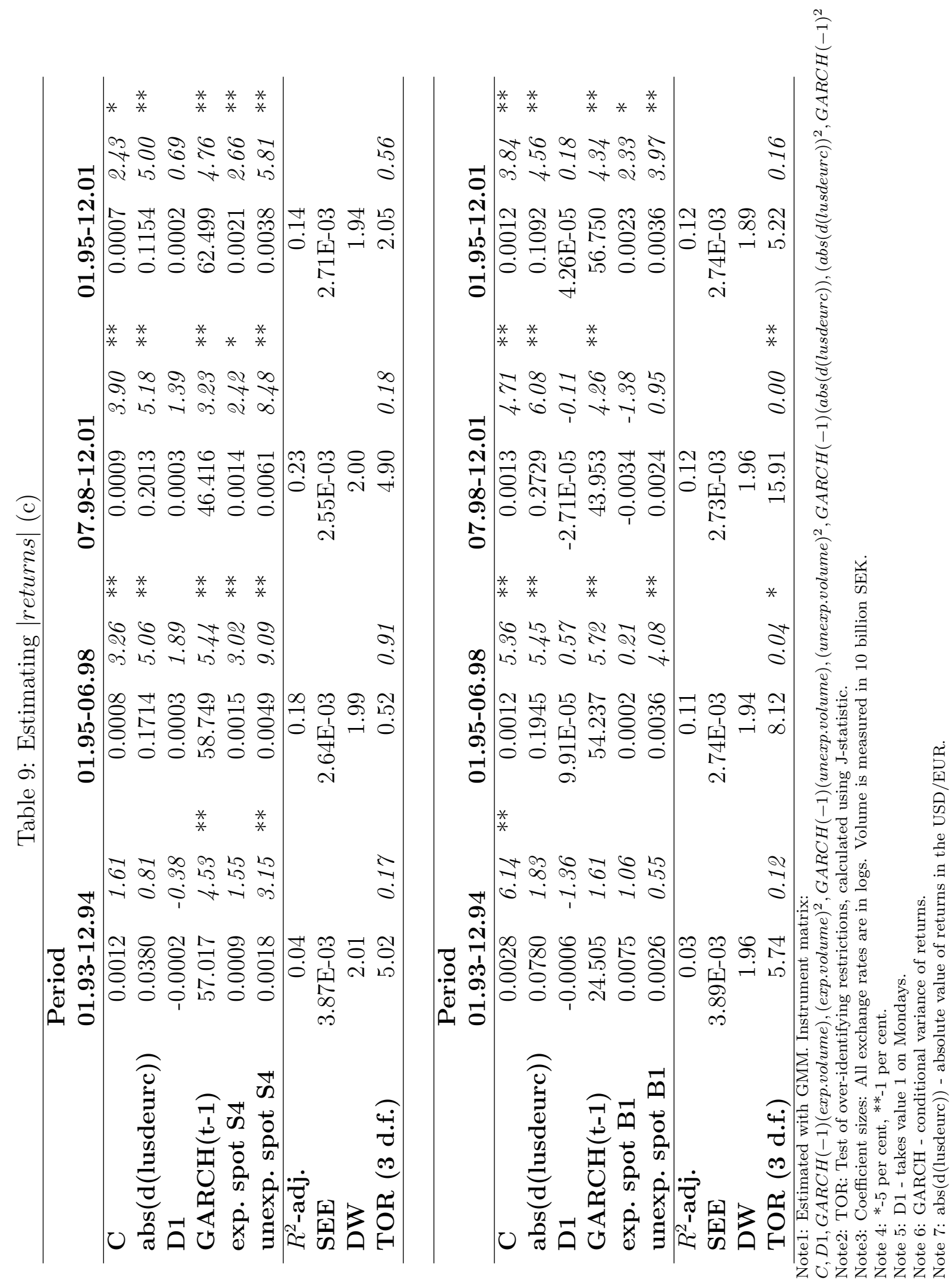




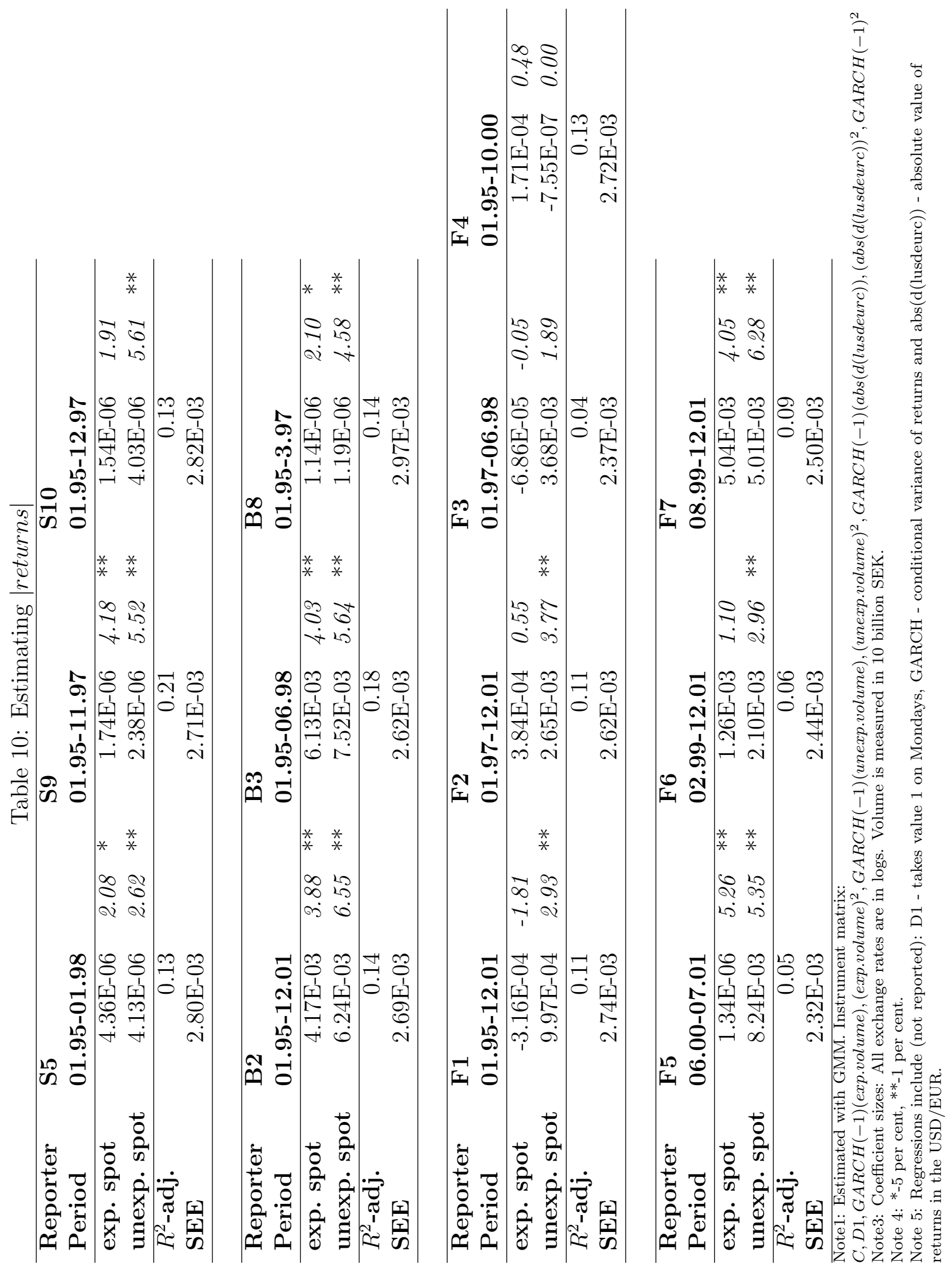


Table 11: Size effects, spot volume -01.1995 to 12.01

\begin{tabular}{lrrrr}
\hline & St.dev. & Parameter & $\begin{array}{l}\text { Implied } \\
\text { volatility }\end{array}$ & $\begin{array}{l}\text { \% of } \\
\text { FX-vola. }\end{array}$ \\
\hline abs. returns & $2.91 \mathrm{E}-03$ & & & \\
Unexp. Spot & $\mathbf{1 0 3 7 7}$ & $\mathbf{7 . 3 2 E - 0 4}$ & $\mathbf{7 . 6 0 \mathrm { E } - 0 4}$ & $\mathbf{2 6 . 1 1}$ \\
Unexp. S1 & $\mathbf{2 6 3 9}$ & $\mathbf{3 . 4 7 E - 0 3}$ & $\mathbf{9 . 1 6 E - 0 4}$ & $\mathbf{3 1 . 4 8}$ \\
Unexp. S2 & 2970 & $\mathbf{3 . 0 7 E - 0 3}$ & $\mathbf{9 . 1 2 E - 0 4}$ & $\mathbf{3 1 . 3 5}$ \\
Unexp. S3 & $\mathbf{1 3 3 7}$ & $\mathbf{4 . 1 8 E - 0 3}$ & $\mathbf{5 . 5 9 E - 0 4}$ & $\mathbf{1 9 . 2 1}$ \\
Unexp. S4 & $\mathbf{1 5 1 0}$ & $\mathbf{4 . 9 2 E - 0 3}$ & $\mathbf{7 . 4 3 E - 0 4}$ & $\mathbf{2 5 . 5 3}$ \\
Unexp. B1 & $\mathbf{8 0 2}$ & $\mathbf{3 . 5 8 E - 0 3}$ & $\mathbf{2 . 8 7 E - 0 4}$ & $\mathbf{9 . 8 7}$ \\
\hline
\end{tabular}

"Per cent of FX-volatility" is the ratio of implied volatility over the standard deviation of absolute returns in the SEK/EUR.

Parameters collected from tables 7-10.

the 13 banks in table 10 we estimate over the whole period where data are available for the respective banks. Only volume coefficients are reported.

As can be seen from the four tables we find that the positive correlation between volume and volatility found for aggregate spot is held up when we instead aggregate for different banks. However, size is of importance. The largest banks, S1 and S2, clearly have the strongest relationship with spot volume. This is confirmed in table 11, where we see that unexpected volume from S1 and S2 in fact explain more of volatility than unexpected volume from aggregate spot volume.

The results presented in 7-10 clearly indicate that different reporters have different impact. This impact is also related to the size of the bank. However, it also seems to be related to the length of the bank's presence in the market. The results in table 10 indicate that banks that are only operating as primary dealers for short periods of time tends to have less correlation between volume and volatility.

The issue of the size of the bank can be tested more thoroughly. In table 12 we have estimated the relationship by grouping reporting banks into three categories, small, medium, and large, according to size of volume. Aggregated the two banks included in "large banks" on average control 41 per cent of daily spot trading. In "medium sized banks" we include four banks that on average control 32 per cent of trading in the spot market.

We see that all groups have a significant effect on volume. The explanatory power of the regressions is however best for the large banks. Since multicolinearity is less of a problem between these three groups we can also test the relationship with all groups together. This is reported in 13 where we again see that it is the largest banks that dominate the volume-volatility relationship indicating a role for heterogenous beliefs. 


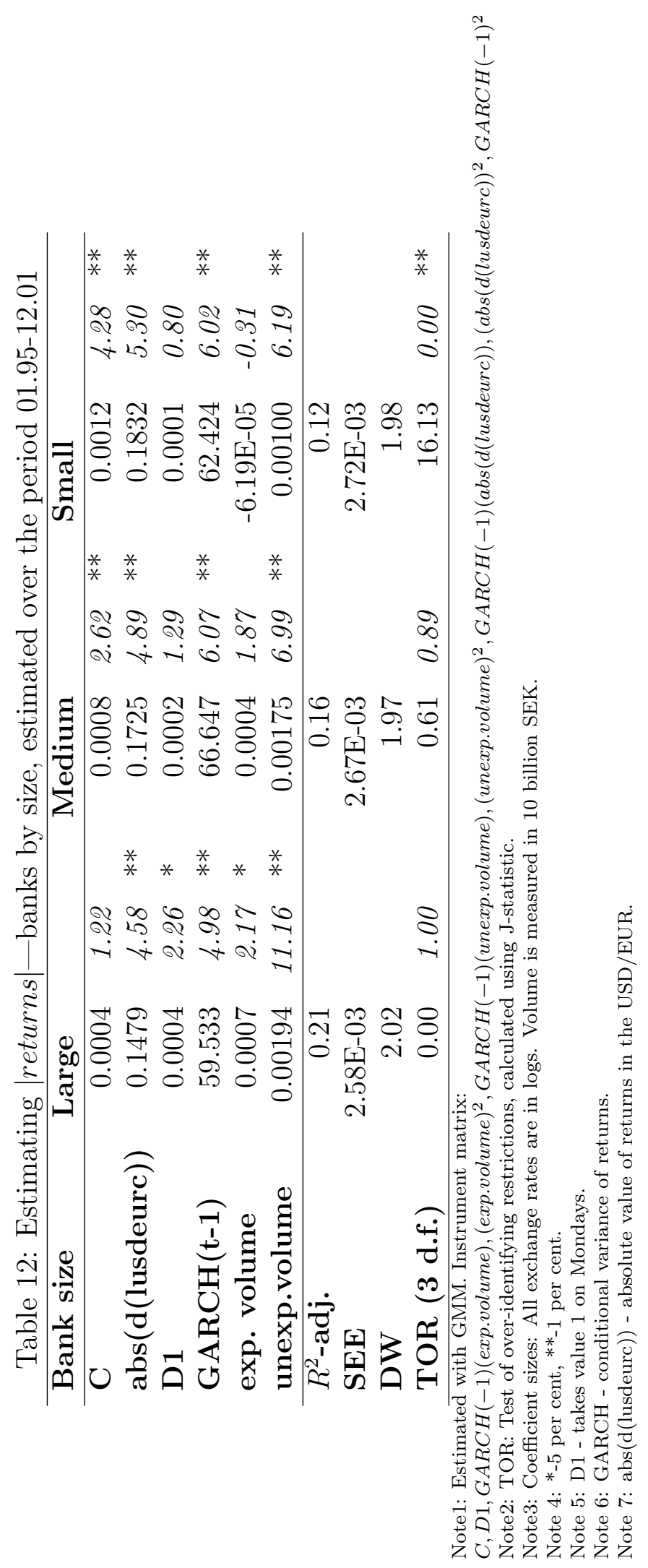




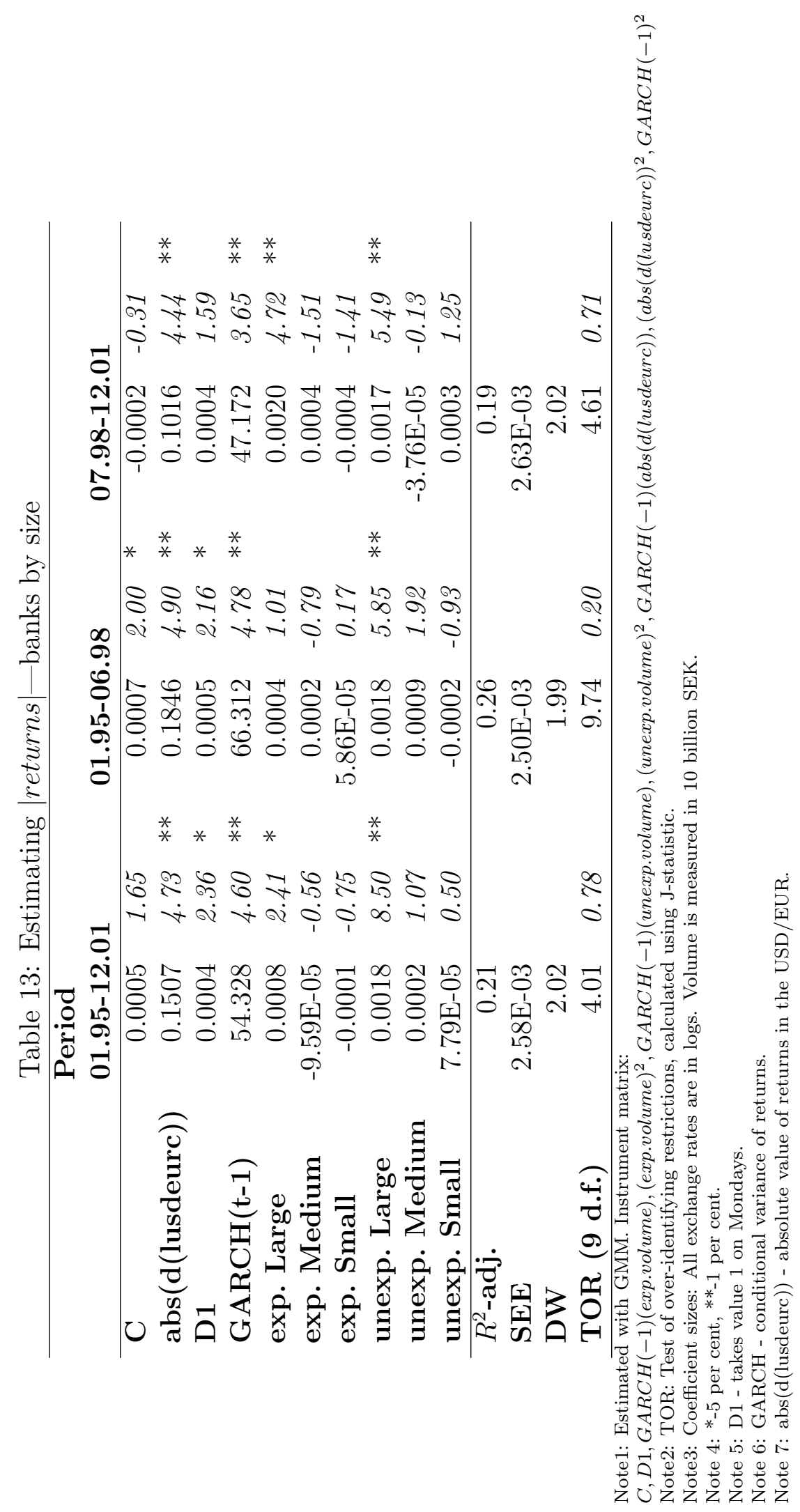




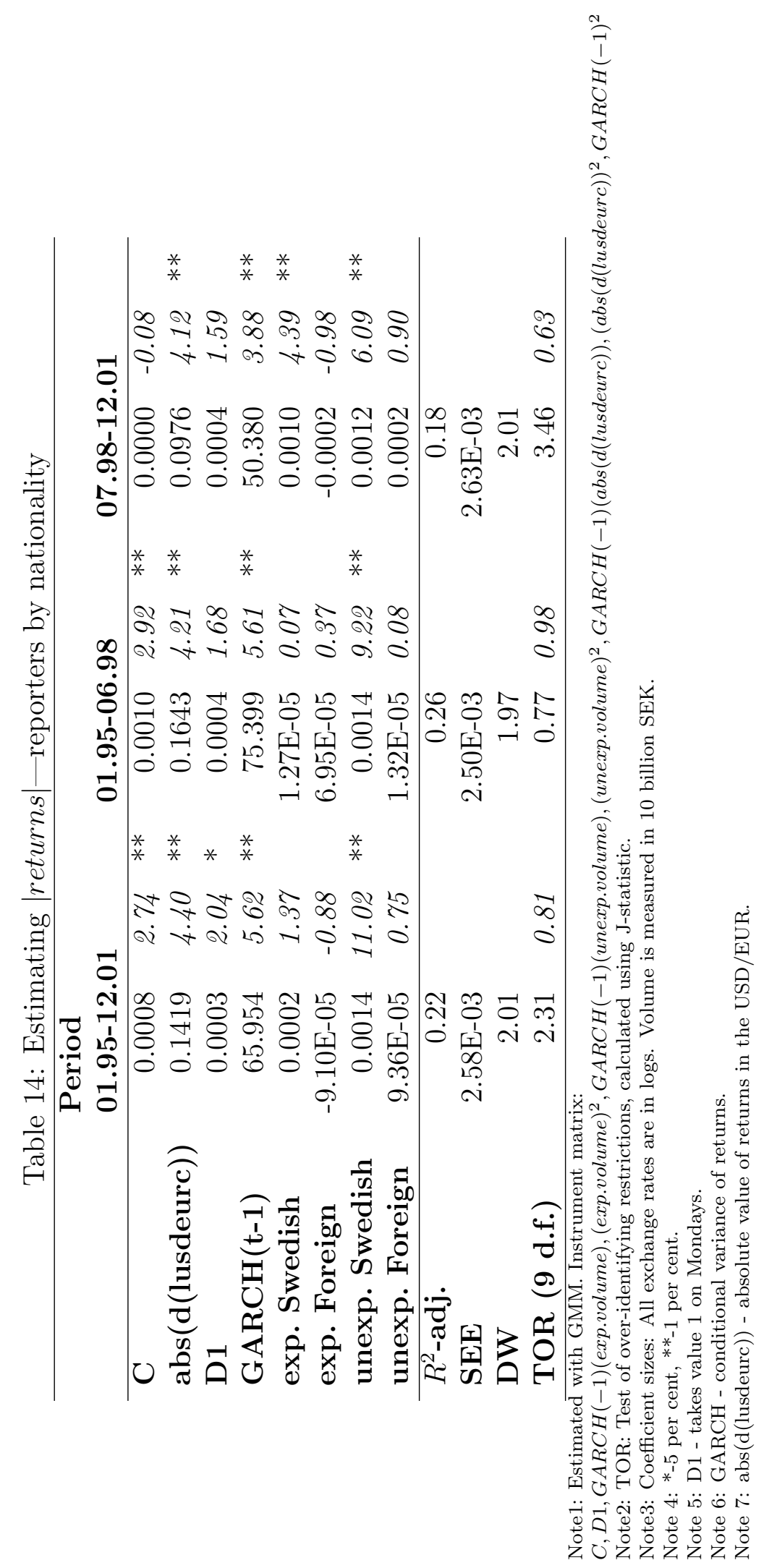


This is further confirmed in table 14 where we group the banks according to whether they are located in Sweden or not. We see that it is the Swedish banks' volume that is significant. These are also the largest banks in the SEK/EUR market, again confirming the size-effect above.

\section{Conclusion}

The literature on volume and volatility asks one primary question: why does the relationship arise? If everyone have the same expectations, and every group behave similarly, the effect should be caused by more trading due to the arrival of new information. However, all rational agents should have the same opportunity to take advantage of the new information, and heterogeneity should be of less importance. On the other hand, if the volumevolatility relationship is the result of dispersion of beliefs, then heterogeneity is certainly a central feature in the analysis.

This paper reviews evidence from a unique set of volume data from the Swedish FX-market, covering five and half years of daily data. The Swedish market is a small market compared with e.g. the USD/EUR or USD/JPY market. However SEK/EUR is among the 10 most traded currency crosses in the world, and the market is well developed with high liquidity. For this market we find evidence to indicate that different agents have different effects on the volume-volatility relationship. In particular we find that it is the volume of the largest banks that is most important. In the SEK-market these banks are Swedish-banks. It is reason to believe that the large Swedish banks are relatively well informed. This in contrast with the result of Daigler and Wiley from future markets that it is the volume of the least informed traders that creates the volume-volatility relationship. While the Daigler and Wiley result is about noise-traders, our result is one about information advantage.

We also document that these differences are of some magnitude. This might indicate evidence of the importance of dispersion of beliefs to understand why volume and volatility display positive correlation. 
A Tables 


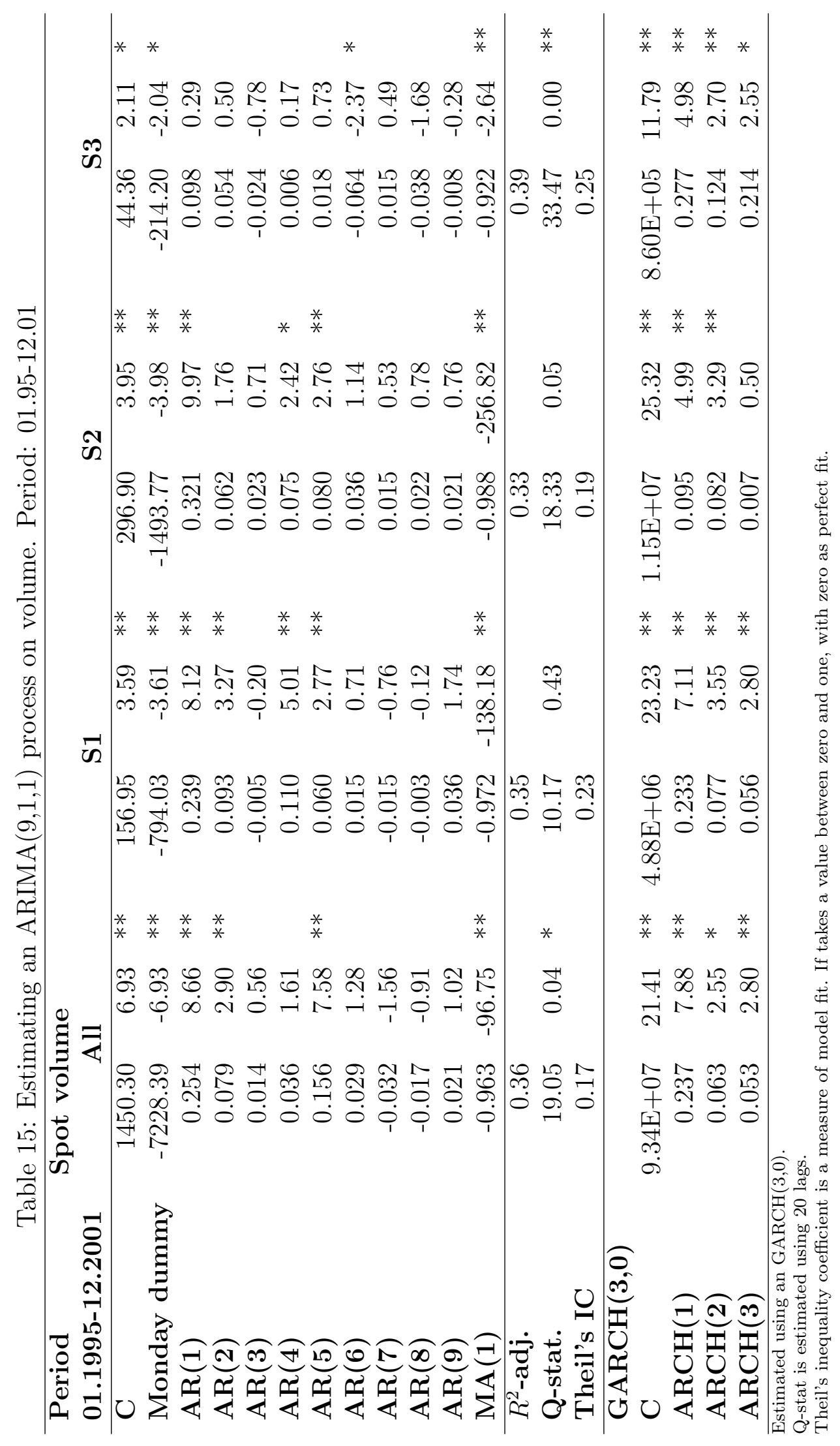


Table 16: Estimation of conditional variance in the SEK/EUR GARCH(1,1) for log-returns 01.93-12.01

\begin{tabular}{|c|c|c|c|}
\hline 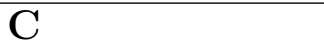 & $2.76 \mathrm{E}-05$ & 0.33 & \\
\hline \multicolumn{4}{|l|}{ Variance } \\
\hline $\mathrm{C}$ & $3.26 \mathrm{E}-07$ & 4.43 & $* *$ \\
\hline ARCH & 0.055 & 9.12 & $* *$ \\
\hline GARCH & 0.929 & 123.15 & $* *$ \\
\hline$R^{2}$-adj. & 0.00 & & \\
\hline F-test (ARCH) & 1.09 & 0.30 & \\
\hline
\end{tabular}

Estimated using GARCH(1,1). 


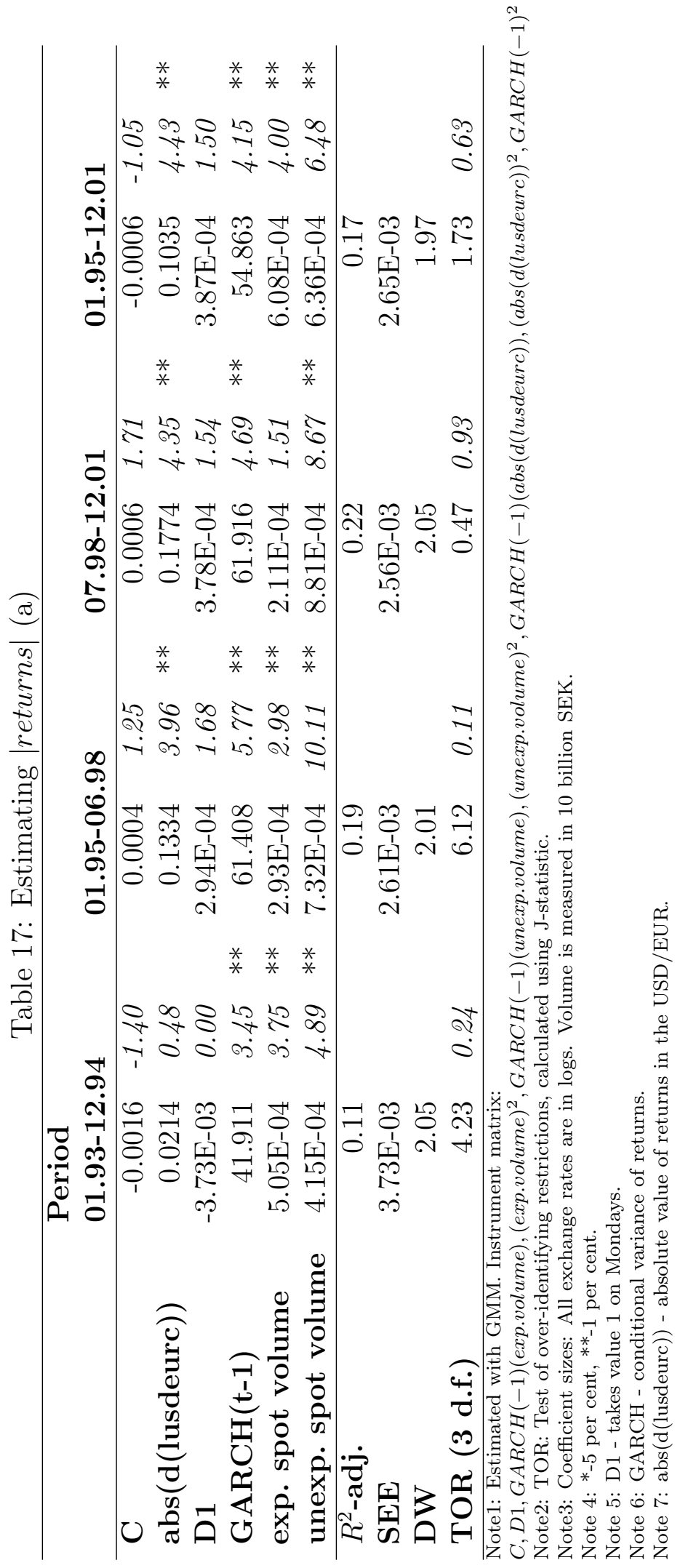




\section{References}

Admati, A. R. and P. Pfleiderer (1988). "A theory of intraday patterns: Volume and price variability." Review of Financial Studies, 1(1), 3-40.

Bank of International Settlements (2002). "Central bank survey of foreign exchange and derivatives market activity." Tech. rep., BIS.

Bessembinder, H. and P. J. Seguin (1992). "Futures-trading activity and stock price volatility." Journal of Finance, 47(5), 2015-2034.

Bessembinder, H. and P. J. Seguin (1993). "Price volatility, trading volume, and market depth: Evidence from futures markets." Journal of Financial and Quantitative Analysis, 28, 21-40.

Bjønnes, G. and D. Rime (2001). "Fx trading ... live! Dealer behaviour and trading systems in foreign exchange markets."

Bollerslev, T. and I. Domowitz (1993). "Trading patterns and prices in the interbank foreign exchange market." Journal of Finance, 48(4), 1421-43.

Chang, E. C., J. M. Pinegar and B. Schachter (1997). "Interday variations in volume, variance and participation of large speculators." Journal of Banking and Finance, 21, 797-810.

Cheung, Y.-W. and M. D. Chinn (2001). "Currency traders and exchange rate dynamics: A survey of the U.S. market." Journal of International Money and Finance, 20(4), 439-71.

Clark, P. K. (1973). "A subordinated stochastic process model with finite variance for speculative prices." Econometrica, 41, 135-55.

Daigler, R. T. and M. K. Wiley (1999). "The impact of trader type on the futures volatility-volume relation." Journal of Finance, 54(6), 2297-2316.

Epps, T. W. and M. L. Epps (1976). "The stochastic dependence of security price changes and transaction volumes: Implications for the mixture-ofdistributions hypothesis." Econometrica, 44, 305-321.

Evans, M. D. and R. K. Lyons (2002). "Order flow and exchange rate dynamics." Journal of Political Economy, 110, 170-180.

Foster, F. D. and S. Viswanathan (1990). "A theory of the intraday variations in volume, variance, and trading costs in securities markets." Review of Financial Studies, 3(4), 593-624. 
Galati, G. (2000). "Trading volumes, volatility and spreads in foreign exchange markets: Evidence from emerging market countries." Working paper 93, Bank for International Settlements.

Goodhart, C. A. and L. Figliuoli (1991). "Every minute counts in financial markets." Journal of International Money and Finance, 10, 23-52.

Grammatikos, T. and A. Saunders (1986). "Futures price variability: A test of maturity and volume effects." Journal of Business, 59, 319-330.

Grinblatt, M. and M. Keloharju (2001). "How distance, language, and culture influence stockholdings and trades." Journal of Finance, 56(3), 1053-73.

Harris, M. A. and A. Raviv (1993). "Differences of opinion make a horse race." Review of Financial Studies, 6(3), 473-506.

Hartmann, P. (1999). "Trading volumes and transaction costs in the foreign exchange market. evidence from daily dollar-yen spot data." Journal of Banking and Finance, 23, 801-24.

Jorion, P. (1996). Risk and Turnover in the Foreign Exchange Market, pp. 19-37. ucp, Chicago.

Karpoff, J. M. (1987). "The relation between price changes and trading volume: A survey." Journal of Financial and Quantitative Analysis, 22(1), 109-26.

Kyle, A. S. (1985). "Continuous auctions and insider trading." Econometrica, 53(6), 1315-35.

Lyons, R. K. (1995). "Tests of microstructural hypothesis in the foreign exchange market." Journal of Financial Economics, 39, 321-51.

Lyons, R. K. (2001). The Microstructure Approach to Exchange Rates. MIT Press, Cambridge, Mass.

Shalen, C. T. (1993). "Volume, volatility, and the dispersion of beliefs." Review of Financial Studies, 6(2), 405-34.

Tauchen, G. E. and M. Pitts (1983). "The price variability-volume relationship on speculative markets." Econometrica, 51, 485-505.

Wei, S.-J. (1994). "Anticipations of foreign exchange volatility and bid-ask spreads." Working Paper 4737, NBER. 